\title{
Sero-prevalence and associated risk factors of Brucellosis among Malaria negative febrile out-patients in Wakiso district, Central Uganda
}

\author{
Samuel Majalija ${ }^{1 *} \mathbb{0}$, Patrick Luyombo $0^{2,3}$ and Gabriel Tumwine ${ }^{2}$
}

\begin{abstract}
Objective: Brucellosis is a zoonotic disease usually acquired through direct contact with the infected animals and consumption of contaminated milk and meat products. In humans Brucellosis presents similar signs with other febrile diseases like Malaria, typhoid and other febrile conditions. This study was carried out to determine the prevalence of Brucella abortus among patients with fever but were negative for Malaria.

Results: A cross-sectional study was carried out in Namayumba Health Centre IV, Wakiso district involving 200 participants. Blood samples was screened for B. abortus using Serum Agglutination Test and confirmed with Tube Agglutination test. A questionnaire was used to collect data on socio-demographic characteristics and human Brucellosis related risk factors. Human B. abortus sero-prevalence was at 7.5\% $(n=200)$. The prevalence was high among participants aged 18-35 years (13.3\%), muslims 12 (14.0\%), those with no formal education (33.3\%) and divorced 2 (14.3\%). Consuming of raw milk (OR 2.162, 95\% Cl 0.021-1.379) and being a Muslim (OR 6.101, 95\% Cl 1.601-23.248) were associated with increased risk of Brucella abortus. It was concluded that human Brucella infection due to Brucella abortus is commonly associated with consumers of raw milk products and muslims in Wakiso district.
\end{abstract}

Keywords: Brucellosis, Brucella abortus, Public health, Raw milk, Zoonoses

\section{Introduction}

Human Brucellosis is a major zoonotic disease of global health importance causing for more than 500,000 new infections every year [1]. In humans the disease is associated with chronic debilitating infections, recurring febrile conditions, joint pains, malaise, fatigue and arthritis resulting in substantial residual disability [2]. Clinical signs in livestock include reduced fertility and abortions which cause severe economic losses to the farmers [3]. The disease is among the top neglected zoonoses that cause severe social economic impact in low income countries like Uganda. Largely human Brucellosis is

\footnotetext{
*Correspondence: saraali67@gmail.com; saraali67@covab.mak.ac.ug ${ }^{1}$ Department of Biosecurity, Ecosystem and Veterinary Public Health, College of Veterinary Medicine, Animal Resources and Biosecurity, Makerere University, P.O. Box 7062, Kampala, Uganda

Full list of author information is available at the end of the article
}

caused by two species of B. abortus and B. melitensis [4], acquired through contact with infected animals, their tissues and products [2]. It is an occupational hazard to persons engaged in high risk professions especially the veterinarians; laboratory, slaughterhouse workers, and farmers $[5,6]$. Other risk factors are associated with Brucellosis, include consumption of raw or unpasteurized milk and dairy products processed from such milk $[7,8]$.

The lack of sufficient data is the reason as to why the true incidence of Brucellosis remains unclear in low and middle-income Brucellosis-endemic countries, Nonetheless, previous reports indicate in the Middle East, Mediterranean region, Northern and Sub-Saharan Africa; human Brucellosis prevalence range from 5 to $55 \%$; and 8 to $46 \%$ in animals [3,9-11]. In Uganda a prevalence of $7-42.2 \%$ among cattle and goats has been reported [12], posing a big threat to abattoir workers and consumers. 
Human Brucellosis sero-prevalence was at 17\% among agro-pastoral communities in Kiboga district, Central Uganda and therefore an important public health problem [8].

Equally, Malaria is an endemic disease in Uganda with prevalence as high as $70 \%$ in patients with pyrexia of unknown origin [13]. In a previous study, $73 \%$ of patients with joint pain, general malaise, and constant headache were infected with Malaria and 13.3\% had Brucellosis [6]. Of greatest concern, however, is the lack of distinguishing clinical features between Malaria and human Brucellosis which confounds diagnosis in absence of laboratory confirmation [14]. Routinely patients with febrile conditions are screened and treated for Malaria as recommended [15], on the other hand, patients with Brucellosis are prone to misdiagnosis and erroneous treatment for Malaria. Such individuals suffer from protracted ill-health and fail to conduct their daily activities, through being unwell $[7,16]$. Several studies focusing on prevalence of human Brucellosis in Africa and Uganda in general have been reported [3,8-11], however, there is scanty information on the prevalence of Brucellosis among the febrile non-Malaria cases. This study therefore determined the sero-prevalence of Brucellosis as well as risk factors associated with occurrence of the disease among febrile non-Malaria out-patients attending Namayumba health centre IV in Uganda.

\section{Main text \\ Methods \\ Study design, site and population}

A cross sectional study was carried out among 200 outpatients at Namayumba Health Centre IV and presenting with fever at the time of seeking medical care between January and March 2016. The study excluded infants, patients without fever, and confirmed febrile Malaria positive patients. The sample size was determined as previously described [17], at 95\% confidence interval (CI) and presumed sero-prevalence of $17 \%$ [8]. The strategic location of Namayumba Health Centre IV along the highway enables the communities from 15 villages of Wakiso district ease access to the health facility.

To establish the associated risk factors for Brucellosis information on patient identification, socio-demographic data, economic activity, feeding habits and knowledge was obtain using a questionnaire survey.

A venipuncture on the brachial vein was used to obtain 3-5 ml of blood collected into plain sterile vacutainer and allowed to clot at room temperature. Serum was harvested by centrifugation at $3000 \mathrm{rpm}$ for $5 \mathrm{~min}$ and stored in serum vials and kept at $4{ }^{\circ} \mathrm{C}$. Later, vials were transported on ice to the central diagnostic laboratory at the College of Veterinary Medicine, Animal Resources and Biosecurity, Makerere University for further processing. In the laboratory, Rose Bengal Plate Test (RBPT) and Serum Agglutination Test (SAT) [18] were carried out using B. abortus antigens (Veterinary Laboratory Agency, VLA, Weybridge, United Kingdom) to detect the Brucella antibodies. Only samples that gave signals for both RBPT and SAT with a titer of 1:160 or greater indicated sero-positivity were considered positive as recommended by OIE and other reports [19].

\section{Data management and analysis}

Data collected was recorded in the Laboratory record book, later entered into excel and transferred to the Statistical Package for Social Scientists (SPSS) software version 18 for analysis. Prevalence was obtained by descriptive analysis where frequencies and proportions were obtained. Risk factors were analyzed at univariate and bivariate level, using Chi square and $\mathrm{p}$ values $<0.005$ were taken as statistically significant. Those that turn out to be statistically significant were further subjected to multivariate analysis to eliminate confounders at $95 \%$ confidence interval (CI).

\section{Results}

\section{Demographic characteristics of the study population}

Table 1 presents descriptive characteristics of the participants. A total of 200 human participants were involved in the study. The age ranged from 5 to 62 years with overall average age of $44.7( \pm 13.0)$ years with the majority $41.5 \%$ $(\mathrm{n}=83)$ in $18-35$ age group. A majority were female $55.5 \%(n=111)$, employed $34.0 \%(n=68)$, had primary education $51.5 \%(n=103)$; $57.0 \%(n=114)$ were Christians and more than a half of the participants were married $61.5 \%(\mathrm{n}=123)$.

\section{The sero-prevalence of Brucellosis in the study population}

The overall sero-prevalence of Brucellosis among the 200 participants was $7.5 \%(n=15)$ as shown in Table 2. It was highest among participants aged 18-35 years (13.3\%, $\mathrm{n}=11)$, varied among males $(7.9 \%, \mathrm{n}=7)$ and females $(7.2 \%, \mathrm{n}=8)$. The prevalence was also higher among Muslim (14.0\%, $\mathrm{n}=12)$, divorced $(14.3 \%, \mathrm{n}=2)$, and among employed $(10.3 \%, n=7)$ participants. Most of the social-demographic factors were not associated $(\mathrm{p}>0.05)$ with the occurrence of $B$. abortus except age $(\mathrm{p}=0.031)$ and religion $(\mathrm{p}=0.003)$ (Table 2$)$.

\section{Risk factors for Brucellosis in the study population}

Aside from the consumption of raw milk which was significantly associated with Brucellosis infection $(p=0.038)$, the rest of the potential risk factors did not have any significant influence (Table 3 ). 
Table 1 Descriptive socio-demographic characteristics of $B$. abortus among participants

\begin{tabular}{lcc}
\hline Characteristics & Frequency $\mathbf{( n )}$ & $\begin{array}{c}\text { \% participants } \\
\mathbf{( 9 5 \% ~ C I ) ~ N = 2 0 0}\end{array}$ \\
\hline Sex & & \\
Male & 89 & $44.5(38.0-51.5)$ \\
Female & 111 & $55.5(48.5-62.0$ \\
Age (years) & & \\
$<17$ & 46 & $23.0(17.5-29.0)$ \\
18-35 & 83 & $41.5(34.5-48.0)$ \\
$>35$ & 71 & $35.5(29.0-42.5)$ \\
Religion & & \\
Christian & 114 & $57.0(50.5-63.5)$ \\
Muslim & 86 & $43.0(36.5-49.5)$ \\
Occupation & & \\
Employed & 68 & $34.0(27.5-41.0)$ \\
Unemployed & 65 & $32.5(26.0-39.5)$ \\
Self employed & 60 & $30.0(24.0-36.5)$ \\
Others & 7 & $3.5(1.0-6.0)$ \\
Education level & & \\
None & 3 & $1.5(0.0-3.5)$ \\
Primary & 103 & $51.5(44.5-58.5)$ \\
Secondary & 78 & $39.0(32.0-46.0)$ \\
Tertiary & 16 & $8.0(4.5-12.0)$ \\
Marital status & & \\
Married & 123 & $61.5(55.0-68.0)$ \\
Single & & $31.5(25.0-38.0)$ \\
Divorced & & \\
\hline & & \\
& &
\end{tabular}

Both socio-demographic and potential risk factors that showed p-values $<0.05$ in the bivariate analysis were considered and included in the final multivariable regression model. Consumption of raw milk (OR 2.162, 95\% CI 0.021-1.379) and being a Muslim (OR 6.101, 95\% CI 1.601-23.248), increased the odds of being infected with B. abortus among participants.

\section{Discussion}

Brucellosis occurs naturally in animals, while humans get infected through contact with the infected animal and consumption of contaminated animal products $[2,20]$. Therefore, it has been shown that prevalence of human Brucellosis tends to correspond to that in animals [21, 22].

In the present study, $B$. abortus sero-prevalence was $7.5 \%$ which is in congruence with $8 \%$ human prevalence of Brucellosis reported in Egypt and 10\% among abattoir worker in Uganda [12]. However, the overall prevalence is expected to be higher than was observed because only febrile non- Malaria cases were tested for Brucellosis. Individual cases with Malaria plus Brucellosis were no
Table 2 Prevalence of $B$. abortus among participants

\begin{tabular}{lccc}
\hline Characteristics & Frequency & +ve B. abortus $(\mathbf{n}$, \%) & p-value \\
\hline Sex & & & \\
Male & 7 & $7.9(3.4-14.6)$ & 0.861 \\
Female & 8 & $7.2(2.7-11.7)$ & \\
Age (years) & & & \\
$<17$ & 1 & $2.2(0.0-6.5)$ & 0.031 \\
$18-35$ & 11 & $13.3(6.0-21.7)$ & \\
$>35$ & 3 & $4.2(0.0-8.5)$ & \\
Religion & & & \\
Christian & 3 & $2.6(0.0-6.1)$ & \\
Muslim & 12 & $14.0(7.0-22.1)$ & \\
Occupation & & & \\
Employed & 7 & $10.3(2.9-17.6)$ & \\
Unemployed & 2 & $3.1(0.0-7.7)$ & \\
Self employed & 6 & $10.0(3.3-18.3)$ & \\
Others & 0 & $0.0(0.00-0.00)$ & \\
Education level & & & \\
None & 1 & $33.3(0.00-100)$ & \\
Primary & 8 & $7.8(2.9-13.6)$ & \\
Secondary & 5 & $6.4(1.3-12.8)$ & \\
Tertiary & 1 & $6.3(0.0-18.8)$ & \\
Marital status & & & \\
Married & 12 & $9.8(4.1-15.4)$ & \\
Single & 1 & $0.0-4.8)$ & \\
Divorced & 2 & $0.0-35.7)$ & \\
\hline
\end{tabular}

included in the study, whereas, previous studies have reported Malaria-Brucellosis co-infections in febrile cases [23]. In concurrence, with this observation, earlier studies reported much higher prevalence of $21.2 \%$ among patients with febrile clinical signs and $44 \%$ prevalence was reported among butcher workers in northern Nigeria $[24,25]$.

In our study, consumption of raw milk, and being a Muslim were risk factors associated with $B$. abortus. Evidently, consumers of raw or unpasteurized milk were two times more likely to test positive for $B$. abortus than those who don't. This is in not surprising since Brucella positive cows shed the organisms in milk which is a major vehicle for human Brucella infection [20,26, 27]. This finding also strengthens the argument that humans get infected through consumption of contaminated animal products as earlier reported [5, 27]. Therefore, efforts to reduce human Brucella infection should target provision of pasteurized milk or milk boiling centres from where the communities can access treated safe milk. The provision milk boiling centres has been suggested as an affordable option that would greatly reduce risk of Brucellosis without affecting livelihoods of the poor people associated with the milk production and dairy value chain in Uganda [21]. 
Table 3 Potential risk factors for the occurrence of $B$. abortus among humans

\begin{tabular}{|c|c|c|c|c|c|}
\hline Attribute & Frequency (n) & $\begin{array}{l}\% \text { participants } \\
N=200\end{array}$ & $\begin{array}{l}\text { Positive B. abortus } \\
(\mathrm{n}, \%)\end{array}$ & Unadjusted OR (95\% Cl) & p Value \\
\hline \multicolumn{6}{|c|}{ Have animals at home } \\
\hline No & 101 & 50.5 & $5(5.0)$ & $2.157(0.710,6.556)$ & 0.167 \\
\hline Yes & 99 & 49.5 & $10(10.1)$ & & \\
\hline \multicolumn{6}{|c|}{ Knowledge on Brucella } \\
\hline No & 140 & 70.0 & $14(10.0)$ & $0.153(0.020,1.188)$ & 0.064 \\
\hline Yes & 60 & 30.0 & $1(1.7)$ & & \\
\hline \multicolumn{6}{|c|}{ Consume raw milk } \\
\hline No & 172 & 86.0 & $2(1.2)$ & $0.921(0.884,0.960)$ & 0.038 \\
\hline Yes & 28 & 14.0 & $13(46.4)$ & & \\
\hline \multicolumn{6}{|c|}{ Consume milk products } \\
\hline No & 163 & 81.5 & $10(6.1)$ & $2.391(0.765,7.468)$ & 0.124 \\
\hline Yes & 37 & 18.5 & $5(13.5)$ & & \\
\hline \multicolumn{6}{|c|}{ Share water source with animals } \\
\hline No & 174 & 87.0 & $15(8.6)$ & $0.914(0.873,0.956)$ & 0.120 \\
\hline Yes & 28 & 13.0 & $0(0.0)$ & & \\
\hline \multicolumn{6}{|c|}{ Deal with animal products } \\
\hline No & 107 & 53.5 & $6(5.6)$ & $1.804(0.617,5.273)$ & 0.276 \\
\hline Yes & 93 & 46.5 & $9(9.7)$ & & \\
\hline
\end{tabular}

The study also observed that being a Muslim was associated with occurrence of $B$. abortus, to the extent that Muslims were six times more likely to test positive for $B$. abortus than Christians. This could be explained by the fact that slaughter of animals with exception of pigs is entirely carried out by muslins in Uganda. These constitute a majority of livestock traders, butchers and others working closely with cattle for slaughter which increases exposure and infection with Brucella organisms. Clearly the religion of muslins has significant influence on the occupational risks and exposure to infected animals with Brucellosis. Our results are supported by other studies that have shown that transmission of Brucellosis can occur through consumption of raw or undercooked meat, blood or offal consumption [5, 28]. These further support the arguments that religion among other factor significantly influence the spread and control of zoonotic diseases in Africa [29, 30].

There was no statistically significant correlation between occurrence of $B$. abortus and having animals at home, knowledge on Brucella, consuming milk product, sharing water source with animal and dealing with animals' products. These findings are in contrast to earlier studies that reported that Brucellosis occurrence in humans was associated with having animals at home [31], consuming milk products [32, 33], sharing water source with animals [34] and dealing with animal products [6, 12]. The variation in the risk factors between Uganda and other countries is likely to be associated with the diverse socio-cultural and anthropological attributes among the various countries.

\section{Conclusion}

Brucella abortus infection among people living in Busiro North, Wakiso district was at $7.5 \%$ which could be a public health concern if not controlled at this moderate prevalence. This study revealed consumption of raw milk and being a Muslim as risk factors associated with $B$. abortus infection in humans. Public awareness campaigns target consumption of treated milk and personnel that handle and slaughter animals in abattoirs to reduce spread of $B$. abortus.

\section{Limitations of the study}

Aside from Brucellosis, other bacterial causes of septicemia leading to fever were not considered which is a shortcoming of our study. This was an oversight which would have given important information on the febrile cases of unknown origin that were negative for Malaria and Brucellosis.

\section{Abbreviations}

RBPT: Rose Bengal Plate Test; SAT: Serum Agglutination Test; SPSS: Statistical Package for Social Scientists.

\section{Authors' contributions}

$\mathrm{PL}, \mathrm{GT}$, and $\mathrm{SM}$ were involved in the study design, made substantial contribution in data analysis and in writing and revising the manuscript. GT and SM supervised field work and laboratory studies. PL was involved in data collection. All authors read and approved the final manuscript. 


\begin{abstract}
Author details
${ }^{1}$ Department of Biosecurity, Ecosystem and Veterinary Public Health, College of Veterinary Medicine, Animal Resources and Biosecurity, Makerere University, P.O. Box 7062, Kampala, Uganda. ${ }^{2}$ Department of Biomolecular Resources and Biolab Sciences, College of Veterinary Medicine, Animal Resources and Biosecurity, Makerere University, P.O. Box 7062, Kampala, Uganda. ${ }^{3}$ Namayumba Health Centre IV, Wakiso District, Uganda.
\end{abstract}

\section{Acknowledgements}

The authors acknowledge the National Agriculture Research Organization through CGS for providing he research grant. Mr. Lubowa-Musisi Laboratory Manager of the Microbiology diagnostic Laboratory, College of Veterinary Medicine, Animal Resources and Biosecurity for the support.

\section{Competing interests}

The authors declare that they have no competing interests.

\section{Availability of data and materials}

All relevant data supporting the conclusions of this article are contained within the article.

\section{Consent for publication}

Not applicable.

\section{Ethics approval and consent to participate}

A written informed consent was sought from each of the adults or parent/ guardian for each of the children who participated in the study. Only adults or children whose parents/guardians signed a consent were included in this study.

This study was part of a larger study titled "Developing control strategies for Brucellosis in the Cattle corridor in Uganda" Project Number CGS 2/14/14 at the College of Veterinary Medicine, Animal Resources and Biosecurity (COVAB), Makerere University that was peer reviewed and approved by the College of Health Sciences-Institutional Review Board (CHS-IRB), College of Veterinary Medicine, Animal resources and Biosecurity Institutional Review Board (COVAB-IRB), and Uganda National Council of Science and Technology.

\section{Funding}

This work was funded under the National Agriculture Research Organization (NARO-Uganda) under the CGS grant number CGS2/14/14 for the project entitled "Control strategies for Brucellosis in the cattle corridor of Uganda".

\section{Publisher's Note}

Springer Nature remains neutral with regard to jurisdictional claims in published maps and institutional affiliations.

Received: 3 October 2018 Accepted: 1 November 2018

Published online: 08 November 2018

\section{References}

1. Wernery U. Zoonoses in the Arabian Peninsula. Saudi Med J. 2014;35(12):1455-62.

2. Köse Ş, Serin SS, Akkoçlu G, Kuzucu L, Ulu Y, Ersan G, Oğuz F. Clinical manifestations, complications, and treatment of Brucellosis: evaluation of 72 cases. Turk J Med Sci. 2014;44(2):220-3.

3. McDermott J, Grace D, Zinsstag J. Economics of Brucellosis impact and control in low-income countries. Rev Sci Tech. 2013;32(1):249-61.

4. Whatmore AM, Perrett LL, MacMillan AP. Characterization of the genetic diversity of Brucella by multilocus sequencing. BMC Microbiol. 2007;7(1):34.

5. Franc KA, Krecek RC, Häsler BN, Arenas-Gamboa AM. Brucellosis remains a neglected disease in the developing world: a call for interdisciplinary action. BMC Public Health. 2018. https://doi.org/10.1186/ s12889-017-5016-y.

6. Mutanda L. Selected laboratory tests in febrile patients in Kampala, Uganda. East Afr Med J. 1998;75(2):68-72.
7. Welburn SC, Beange I, Ducrotoy MJ, Okello AL. The neglected zoonoses-the case for integrated control and advocacy. Clin Microbiol Infect. 2015:21(5):433-43.

8. Tumwine G, Matovu E, Kabasa JD, Owiny OD, Majalija S. Human Brucellosis: sero-prevalence and associated risk factors in agro-pastoral communities of Kiboga District, Central Uganda. BMC Public Health. 2015;15:900.

9. Al-Talafhah AH, Lafi SQ, Al-Tarazi Y. Epidemiology of ovine Brucellosis in Awassi sheep in Northern Jordan. Prev Vet Med. 2003;60(4):297-306.

10. Pappas G, Papadimitriou P, Akritidis N, Christou L, Tsianos EV. The new global map of human Brucellosis. Lancet Infect Dis. 2006;6:91-9.

11. Musallam II, Abo-Shehada MN, Hegazy YM, Holt HR, Guitian FJ. Systematic review of Brucellosis in the Middle East: disease frequency in ruminants and humans and risk factors for human infection. Epidemiol Infect. 2016;144(4):671-85.

12. Nabukenya I, Kaddu-Mulindwa D, Nasinyama GW. Survey of Brucella infection and Malaria among Abattoir workers in Kampala and Mbarara Districts, Uganda. BMC Public Health. 2013;13:901.

13. Franco PM, Mulder M, Gilman HR, Smits LH. Human Brucellosis, review. Lancet Infect Dis. 2007;7:775-86.

14. Chikeka J, Dumler S. Neglected bacterial zoonoses. Clin Microbiol Infect. 2015. https://doi.org/10.1016/j.cmi.2015.04.022

15. Uganda Malaria Reduction Strategic Plan, 2014-2020. http://health.go. ug/programs/national-Malaria-control-program. Accessed 26 Aug 2018.

16. Feder HM, Salazar JC. A clinical review of 105 patients with PFAPA (a periodic fever syndrome). Acta Paediatrica. 2010;99(2):178-84.

17. Thrushfield M. Veterinary epidemiology. 3rd ed. Oxford: Black Well Science; 2005.

18. Alton GG, Jones LM, Angus RD, Verger JM. Serological methods. In: Alton GG, editor. Techniques for the Brucellosis laboratory. Paris: Institute National de la Recherche Agronomique; 1988. p. 13-61.

19. Díaz R, Casanova A, Ariza J, Moriyón I. The Rose Bengal Test in Human Brucellosis: a neglected test for the diagnosis of a neglected disease. PLoS Negl Trop Dis. 2011. https://doi.org/10.1371/journal.pntd.0000950.

20. WHO. Brucellosis in humans and animals. 2006. http://www.who.int/csr/ resources/publications/Brucellosis.pdf. Accessed 15 Aug 2018.

21. Makita K, Fèvre EM, Waiswa C, Eisler MC, Welburn SC. How human Brucellosis incidence in Urban Kampala can be reduced most efficiently? A stochastic risk assessment of informally-marketed milk. PLoS ONE. 2010. https://doi.org/10.1371/journal.pone.0014188.

22. Seleem MN, Boyle SM, Sriranganathan N. Brucellosis: a re-emerging zoonosis. Vet Microbiol. 2010;40(3-4):392-8.

23. Badiaga S. Imported Brucellosis associated with Plasmodium falciparum Malaria in a traveler returning from the tropics. J Travel Med. 2005; 12(5):282-4

24. Ducrotoy MJ, Bertu WJ, Ocholi RA, Gusi AM, Bryssinckx W, Welburn S, Moriyon I. Brucellosis as an emerging threat in developing economies: lessons from Nigeria. PLoS Negl Trop Dis. 2014;8(7):e3008.

25. Muriuki S, McDermott J, Arimi S, Mugambi J, Wamola I. Criteria for better detection of Brucellosis in the Narok District of Kenya. East Afr Med J. 1997;74(5):317-20.

26. Jennings GJ, Hajjeh RA, Girgis FY, Fadeel MA, Maksoud MA, Wasfy MO, Earhart K. Brucellosis as a cause of acute febrile illness in Egypt. Trans R Soc Trop Med Hyg. 2007;101(7):707-13.

27. Omore A, Arimi S, Kangethe E, McDermott J, Staal S, Ouma E, Koroti E. Assessing and managing milk-borne health risks for the benefit of consumers in Kenya. Ministry of Agriculture and Rural Development, Nairobi Kenya. 2002. https://core.ac.uk/download/pdf/132664346.pdf. Accessed on 10 July 2018.

28. Corbel MJ. Brucellosis in humans and animals. Food and Agriculture Organization of the United Nations, World Health Organization \& World Organisation for Animal Health. 2006. http://www.who.int/iris/handl e/10665/43597. Accessed 16 Aug 2018.

29. Chand P, Chhabra R. Herd and individual animal prevalence of bovine Brucellosis with associated risk factors on dairy farms in Haryana and Punjab in India. Trop Anim Health Prod. 2013;45(6):1313-9.

30. Manguvo A, Mafuvadze B. The impact of traditional and religious practices on the spread of Ebola in West Africa: time for a strategic shift. Pan Afr Med J. 2015. https://doi.org/10.11694/pamj.supp.2015.22.1.6190. 
31. Alballa S. Epidemiology of human Brucellosis in southern Saudi Arabia. J Trop Med Hyg. 1995;98(3):185-9.

32. Cooper CW. Risk factors in transmission of Brucellosis from animals to humans in Saudi Arabia. Trans R Soc Trop Med Hyg. 1992;86(2):206-9.

33. Husseini AS, Ramlawi AM. Brucellosis in the West Bank, Palestine. Saudi Med J. 2004;25(11):1640-3.
34. Mugabi R. Brucellosis Epidemiology, virulence factors, control and molecular targets to prevent bacterial infectious diseases. North Dakota State University. 2012. https://library.ndsu.edu/ir/bitstream/handle/10365 /21919/Robert\%20Mugabi.pdf? sequence=1\&isAllowed=y. Accessed 26 Apr 2018.
Ready to submit your research? Choose BMC and benefit from:

- fast, convenient online submission

- thorough peer review by experienced researchers in your field

- rapid publication on acceptance

- support for research data, including large and complex data types

- gold Open Access which fosters wider collaboration and increased citations

- maximum visibility for your research: over 100M website views per year

At BMC, research is always in progress.

Learn more biomedcentral.com/submissions 